\title{
Accelerating the Transition to Equitable, Sustainable, and Livable Cities: Toward Post-Fossil Carbon Societies
}

\author{
Yong Geng ${ }^{1,2,3,4, *}$, Tsuyoshi Fujita ${ }^{5}$, Raimund Bleischwitz ${ }^{6}$, Anthony Chiu ${ }^{7}$, Joseph \\ Sarkis $^{8}$
}

1. School of International and Public Affairs, Shanghai Jiao Tong University, No. 1954 Huashan Road, Xuhui, Shanghai 200030, China

2. China Institute for Urban Governance, Shanghai Jiao Tong University, No. 1954 Huashan Road, Xuhui, Shanghai 200030, China;

3. School of Environmental Science and Engineering, Shanghai Jiao Tong University, No. 800 Dongchuan Road, Minhang, Shanghai 200240, China;

4. Shanghai Institute of Pollution Control and Ecological Security, Shanghai 200092, China.

5. Center for Social and Environmental Systems Research, National Institute for Environmental Studies (NIES), 16-2 Onogawa, Tsukuba-City, Ibaraki 305-8506, Japan;

6. Institute for Sustainable Resources, Bartlett School of Environment, Energy and Resources, University College London, London WC1H 0NN, United Kingdom;

7. Department of Industrial Engineering, De La Salle University, Manila, Philippine;

8. Worcester Polytechnic Institute, Worcester, Massachusetts, 01609-2280 USA;

*Corresponding Author

Yong Geng,

School of International and Public Affairs,

Shanghai Jiao Tong University,

No. 1954 Huashan Road, Xuhui,

Shanghai 200030, China

Email: ygeng@sjtu.edu.cn

Phone: 0086-21-62932103

\begin{abstract}
Rapid urbanization brought many environmental issues, leading to an urgent need on urban environmental governance. This special issue aims to focus on such a topic so that cities can accelerate their transition to equitable, sustainable, and livable Cities. Twenty-six papers were selected in this special issue, with different foci on different topics in different cities. These papers can be categorized into the following: reviews, policy orientations, metric and indicators, consumer behaviors and lifestyles, innovative designs and implementations, and tools. These papers discuss various topics related with urban environmental governance and can provide valuable insights to those city managers so that they can improve their environmental governance and move their cities toward post-fossil carbon societies. By summarizing the key contributions of these papers, an integrated framework on effective urban environmental governance is proposed so that cities can increase their resources efficiency, reduce overall waste production, and respond global climate change.
\end{abstract}

Keywords: Urban environmental governance; urban transition; low carbon society; 
equitable city; sustainable city; livable city.

\section{Introduction}

Urbanization is a global phenomenon. Approximately $64 \%$ population in the developing world and $86 \%$ population in the developed world will reside in urban areas by 2050. Urbanization has consequences; environmental, social, economic, and political systems accrue both benefit and burdens. The rate of urbanization is increasing globally and the challenges of meeting UN Sustainable Development Goal of sustainable cities (SDG 11) are manifold.

Urbanization benefits exist due to improved infrastructure, job opportunities, and some increases in freedom amongst networks. Social services improve through greater concentration of resources. City planners and elected officials are aware that they need to provide resources, infrastructure, and services to meet the needs of a growing number of citizens.

Rapid urbanization can be deleterious. A range of problems emerge. Socio-economic inequalities, increasing slums and informal settlements, urban sprawl and severe urban ecosystem degradation become ubiquitous. Examples appear and are relatively consistent, no matter the location of the urbanization. For example, resource inequities from spatial formation of cities tend to follow patterns. Wealthier households sprawl outwards into emerging suburban environments. Lower urban socio-economic populations literally and figuratively migrate to the peripheries of society. Vulnerable populations are marginalized by prioritizing infrastructure development in wealthier suburban regions. Authorities abandon poor urban areas. These events increase urban decay and pollution.

Amongst these urban issues, managing urban environmental pollution is especially challenging. This issue has become increasingly critical and needs attention with effective science, policy, and action. Environmental issues are diverse, particularly at the municipal level. These environmental issues include air and water pollution, biodiversity losses, hazardous and solid waste, resource depletion, power-grid cyber disruption, and climate change (Tian et al., 2016).

To address these concerns requires different stakeholders to make transdisciplinary efforts. There is a requirement for technical, scientific, institutional, and social efforts to address current and emergent problems. Several urban locations have responded by initiating different and unique programs. Energy management, climate change adaptation, improved resource efficiency, smart recycling systems, and environmentally friendly transportation planning are example efforts (Geng et al., 2019; Czischke and Pascariu, 2015; Fujii et al., 2014; Gil and Duarte, 2013).

However, these policies have either focused on a single issue, or have been implemented without a systematic, holistic perspective. Lack of policy integration cannot effectively address complicated, interconnected, wicked problems, leading to 
ineffective, inefficient, and sometimes counterproductive policy deployment (Runhaar et al., 2009).

Multidisciplinary advancing to transdisciplinary studies can capture the dynamics of urban resource flows. The assessment should cover resources across demographics and geographies. This approach helps prepare the most effective urban policies for improving the overall quality of life and poverty reduction; maintaining consistency with the United Nations sustainable development goals (SDGs).

Improving knowledge on resource and material flows within and outside cities is an essential step. These flows will inform how various groups are favored or marginalized. The flows also inform which policies can mitigate overall environmental impact of urbanization, and it fits into research priorities identified by Bai et al. (2018).

This special issue bridges multiple gaps across disciplines; the science of cities, geography, social, environment, sustainability, economic planning, and policy. The key academic contributions from this special issue provide valuable insights to multiple levels of analysis and application. Local governments, the Intergovernmental Panel on Climate Change (IPCC), Global Environmental Facility (GEF), the World Bank, and the UN-Environment Programme's International Resource Panel can each benefit. Urban planning and design, urban assessment, urban development strategies, and indicators frameworks will also benefit at the planning implementation levels of study and practice.

In total, twenty-six papers were selected in this special volume, seeking to address the various issues we have identified. The different perspectives in these papers include: reviews, policy orientations, metric and indicators, consumer behaviors and lifestyles, innovative designs and implementations, and tools to accelerate the transitions to promote equitable, sustainable and livable cities. It is this order that we provide an overview of the works published. But, overlaps and interlinkages amongst the perspectives and topics also exist.

\section{Review papers on urban environmental governance}

One review paper was included in this special issue, and it was on the topic of urban environmental governance. Wu et al. (2018) in their study identify 1,697 articles published in the Web of Science index. These articles were published during a twentyyear period from 1997 to 2017. Research keywords for the search, in addition to urban environmental governance included GHG emissions, energy, water, health and transport.

The structured review included bibliometric and network analysis. Their results show that the overall publication quantity had gradually increased over the years. The top three journals that produced this research stream included the Journal of Cleaner Production, Sustainability, and Energy Policy. Interestingly, the Journal of Cleaner 
Production and Sustainability are general outlets and it is not surprising that the general journals played a large role. But, the inclusion of Energy Policy, shows how important energy resources and use are to urban environmental governance.

The USA as a country had the most publications and international co-authorships. China and the UK followed. These are not surprising results since these countries typically represent the greatest output in English language scientific journals across disciplines. The Chinese Academy of Sciences was the most influential, in terms of productivity, in this area.

Life cycle assessment and ecological footprints were dominant approaches, placing the work mostly on environmental rather than decision making or technological basic science methodologies. As will be seen in this special issue, a multitude of other modeling approaches can prove especially salient.

Given the environmental focus of this research paper, it can help identify emergent areas of importance, but also serve as a guidance for policy makers on where investment in research has occurred and what gaps still exist. From an academic point of view, the authors suggest that it is crucial to combine different methods so that more innovative perspectives are investigated.

\section{Policies on urban environmental governance}

Under growing climate change and environmental impacts, urban governance should integrate environmental infrastructure, land use, and comprehensive socio-economic policies. Five papers investigate the main barriers that impede effective joint urban environmental, social, and economic governance. They identify and recommend relevant policies and regulations to improve effectiveness and linkage to previous implementations.

The first paper in this special issue on policies is by Li et al. (2019a). They propose urban governance policies to promote the research and implementation of new energy vehicles (NEV) technologies.

The authors utilize data envelopment analysis (DEA) and random effects models. Panel data from 148 automobile industry firms in the Zhongguancun Science Park in Beijing Metropolitan Region for the period of 2005 to 2015 are used in this study. Firm size, government support on related regulations, $R \& D$ investment, size, strength of policy, financial subsidy, firm age, earlier cluster, midterm cluster, ownership, type of main business, and high-tech firms, are found to be significant dependent variables related to firm resource efficiency.

They conclude and propose that China increase governmental support to ensure effective environmental governance for small NEV firms. Key suggestions include: 1) governments should prepare more policies to create a fair and competitive environment; 
2) more financial support to promote technological development process of NEV firms;

3) help protect the innovative capabilities of small NEV firms.

The second paper on this topic is by Fan and Zhou (2019), They investigate the impact of urbanization and real estate investment on carbon emissions in thirty Chinese provinces. They utilize a multiplicative logarithmic mean Divisia index (M-LMDI) model to evaluate spatial panel data for the period of 1997-2015.

The carbon emissions calculation relied on consumption amounts of 17 fossil fuels and the IPCC method. The LMDI model separated carbon emissions into different variables, including carbon emission intensity of unit real estate investment, urban real estate investment per urban population, and ratio of urban population. The results indicate that carbon emissions in the thirty Chinese provinces had increased by 94\% from 1997 to 2015. Real estate per urban population was the most influential driver, followed by the urban population ratio.

The top five provinces in higher carbon emission increases (Shandong, Guangdong, Hebei, Jiangsu and Henan) have the negative impacts from urbanization, causing spillover emission increases in their surrounding provinces. They found that real estate investment impact is limited within each province.

The results from the spatial panel data model find direct impact of urbanization is significantly negative, while the spatial spillover effect is positive. Such results indicate that urban expansion in one province can induce carbon emission increases in neighboring provinces. Conjecture was that this relationship is due to the close supply chain linkages. They propose the inter-provincial spatial management policies to avoid carbon emissions spill-over impacts of urbanization. In particular, they suggest that urbanization policies should consider appropriate real estate investment and urban renovation.

The third paper in the policy focused articles is by Khuong et al. (2019), who evaluate renewable energy policies in ASEAN country urban areas. This study used a varied range of quantitative information for renewable energy policy targets in ASEAN for the period of 1995-2013.

To investigate the importance of renewable energy development in urban governance policy, the authors employ both correlation analysis and decomposition analysis methods. Decomposition analysis helps uncover the key drivers on renewable energy growth rates. Correlation analysis assesses the correlation between renewable energy change and its effect indicators. Their results indicate that the potential of economic growth is associated with urban effects on renewable energy development. This result can ensure rapid economic growth and urbanization. They suggest that urban areas should be the focus of renewable energy policy, and adding socio-economic benefits should be communicated more widely. The authors also recommend multiple actors to 
work together to develop renewable energy supporting schemes for making the urbanization trend environmentally sustainable.

The fourth paper in the policy focused articles is by Weber et al. (2019), who examine the main courses for environmental conflicts related to privatization and deprivatization processes of urban services in 80 German cities. This study used an approach comprising comparative analysis, statistics and political ecology for the period of 1985-2015.

Results from this analysis indicate that de-privatization initiatives and conflicts that may potentially arise from them are frequently driven by grassroots organizations promoting for the provision of commons-based urban services. Consequently, governments should avoid service privatization particularly in the energy, water supply and waste management sectors, as privatizing these services is likely to negatively affect the quality of supply and to increase prices. However, this study indicates that de-privatization initiatives addressing urban services may be less successful (although widely noticeable) within healthcare, social housing, and public spaces, which tend to have a much stronger social relevance. Initiatives aiming at preventing privation rather than promoting de-privatization within these sectors have been more successful. In such a context, social movement campaign for more social and environmental issues should be addressed in the management of public services.

The fifth paper in this category is by Fratini et al., (2019), who conducted an analysis to investigate how cities in Europe, both as actors and places, co-produce the circular economy imaginary. The conceptual framework of "knowledge co-production" was applied in this study. Four elements were utilized under this framework, including discourses, institutions, representations and identities, to classify the characteristics on circular economy in urban contexts.

Based on this framework, they conducted a literature review to show the emergence and developments of circular economy. Then, in order to uncover how circular economy is interpreted in European metropolitan cities, they analyzed relevant policy documents (e.g. plans, white papers, policy briefs, etc.) in three cities in Europe, namely, Amsterdam, Paris and London.

They found that these three cities have engaged in different translations of the circular economy imaginary since they are affected by pre-existing political and institutional arrangements. They also found that there is a need to pay close attention to discourses, institutions, representations and identities that are shaped by the ways in which circular economy imaginaries are developed, mobilized, and operationalized in different contexts. The results of this paper would be useful to develop a research agenda to understand the relationship between policies and existing urban translations of circular economy to provide effective recommendations for making transitions to more sustainable society. 


\section{Consumer behaviors and lifestyles toward post carbon societies}

Effective urbanization environmental governance requires community and citizen participation. Every citizen has local environmental protection responsibility. Citizen and individual consumer behavior and lifestyle requires adaptation. Four papers in this special issue cover this topic, each with a varying perspective and insight.

Schröder et al. (2019) author the first in this topical series. They argue that consumption patterns and lifestyle choices are important urban carbon and material footprint determinants. They initially examine various urban metabolism dimensions. Dimensions include accommodations, transportation, food supply and consumption, and waste management. This study proposes a conceptual transformation framework from unsustainable urbanization toward sustainable consumption and production settings. Social learning and institutional changes are used to support introduction of this framework.

This study argues that the active involvement of non-traditional stakeholders are generally not included in urban planning processes. Consumer organizations, retailers and supermarkets, sharing platforms for mobility and tools, community co-housing initiatives or informal recycling cooperatives do not typically exist in the discourse.

Three case studies help evaluate and refine this framework. Shareable.net in San Francisco, Seoul, and other cities; sustainable food systems in Kyoto, Japan; and cooperative waste recycling and 3D printing in Pune, India are investigated. Transdisciplinarity, co-design, co-creation, participation and visioning, higher order learning, institutional change, and governance innovation, can all be parlayed for urban ecofootprint reduction.

To complement top-down policies, bottom-up initiatives, supported and facilitated through co-creation processes, can achieve institutional change toward urban sustainable consumption and production. Various bottom-up actors can make progress on food, mobility, housing, consumer products, and consumer waste.

The second paper in this series is authored by Valenzuela-Levi (2019). He investigates how income inequality relates to urban recycling rates. The cities of Barcelona and London are the comparison case studies. This study uses mixed-methods, including exploratory qualitative descriptive analysis and panel data fixed and random effects regression.

The major result is that recycling does not necessarily mirror existing inequalities. Using income differences to determine recycling capacities weakens the pace of transition toward sustainability. This approach would make environmental achievements only accessible to the rich. Instead, they propose more equitable distribution of resources for effective recycling services. The issue is both a demand- 
driven phenomenon and how institutions and policies shape the supply-side.

The third paper is authored by Akbari and Hopkins (2019). They use Ho Chi Minh City (HCMC), Vietnam as a unique case study city. They investigate "anywhere working", the practice of performing work tasks remotely instead a traditional fixed office location. They determine whether this practice represents a possible mechanism for reducing traffic congestion and pollution.

The investigators collect primary empirical data on the current working arrangements and commuting habits of HCMC workers using descriptive surveys. Anywhere working organizational policies and relationships to commuter transport, attitudes and concerns toward anywhere working, and perceived worker productivity are studied.

While a significant majority $(74 \%)$ of HCMC commuters would like to engage in anywhere working practices, only $41 \%$ actually do. Managerial decisions are the major reason for this lower practice. This study also finds that the desire to engage in anywhere working is strongest among those who have first-hand experience of working remotely. Their results encourage significant behavioral changes in organizations and amongst management. Modern information and communication technologies (ICTs) can be major enablers for anywhere working. ICTs need to be in city planner and manager plans for assisting cities in becoming more equitable, sustainable, and livable.

The fourth paper in this series is authored by Song et al. (2018). This paper investigates Chinese cities waste generation mechanisms by linking household survey data with life cycle assessment datasets and using Bayesian belief networks (BBN) method, which helps explore the possibilities of food waste reduction using scenario analysis. This study generalizes to further reveal the association of food waste and food security at global scales.

They find that the average food waste varies among Chinese cities ranging from 12-33 kilograms per capita per year. The carbon footprint ranges from 30-96 kilograms of $\mathrm{CO}_{2}$ equivalent per capita per year. They also find that while animal derived food accounts for $5-18 \%$ in waste weight, this source represents $18-40 \%$ of the carbon footprint. By conducting a sensitivity analysis, they further find that refrigerator ownership ranks first in determining food waste generation. These results help to prepare urban residential policies to encourage sustainable food consumption behaviors.

\section{Innovation designs and implementations}

Smart designs and effective implementations of innovative environmental, social, and economic urban governance systems can make progress toward post-carbon societies and circular economies. Five papers on this topic appear in this special issue.

Industrial symbiosis, nexus innovations, urban eco-industrial network, urban energy contract management are examples of innovative thinking for transformation toward 
sustainable urban development.

Shi et al. (2019) introduce a closed-loop supply chain for electronic printer cartridge remanufacturing. E-wastes, printer cartridges are significant urban waste streams $(\mathrm{Qu}$ et al., 2013). This study explores barriers for closed-loop e-wastes supply chains considering three supply chain stages. The stages include collection of used cartridges, remanufacturing, and sales and use of remanufactured cartridges.

This study hypothesizes that barriers come from both the remanufacturer management and government support. This study uses the Decision Making Trial and Evaluation Laboratory (DEMATEL) method. The authors acquired data concerning cause-effect relationships between identified barriers from two Chinese printer cartridge remanufacturers. A barriers causal relationships analysis on governments and enterprises helps provide useful insights.

The DEMATEL study results reveal four prominent barriers for innovative implementation of the closed-loop supply chains. These major barriers include national quality standards for remanufactured printing consumables, low quality of fake and counterfeit printing consumables (damaging reputation of remanufacturers), lack of a certification system for remanufactured printing, and lack of technical standards for remanufacturing of printing consumables.

This study concludes that the prominent barriers occur in remanufacturing management and use of remanufactured cartridges stages. The four prominent barriers have strong networks to other barriers. These four barriers have high cause and effect correlations. These results differ from some previous studies, showing government support is critical. The ultimate study conclusion is that to overcome remanufacturing difficulties remanufacturers need to cooperate with original manufacturers of new cartridges and develop self-owned new remanufacturing technologies.

The second paper in this special issue topic series of papers, authored by Li et al. (2019b), applies an event study method for investigating air quality improvement in Hangzhou, the 2016 G20 city host.

In order to deal with air pollution issues for the event, Hangzhou encouraged technological upgrades to the city's energy infrastructure. The city's major transition was from fossil fuels to clean energies. Cost-benefit analysis evaluated the overall sustainable transformation effort. The project includes long-term benefits analysis rather than only short-term improvements.

The authors propose a long-term strategy to enhance the collaboration with neighboring cities so that the air quality can be maintained for the long term. This spillover investigation was evident in earlier study published in this special issue (Fan and Zhou (2019)). They further suggest that continuous technology updates are necessary 
elements for optimizing the local energy structure.

Chen and Chen (2019), the third paper in this topic category, adopt a systemic and progressive approach to identify carbon emission pathways for the urban built environment section in Hubei Province, China. The methodology relies on a high resolution $\left(0.1^{\circ} \times 0.1^{\circ}\right.$ grid $)$ GIS-based downscaling framework emission inventory.

This study finds that faster renewable energy penetration would make carbon emissions from the building sector peak before 2030. The greatest reductions would occur in more developed cities. Additional energy efficiency improvements upgrading the energy infrastructure leads over a 17\% carbon emission reduction for less developed cities.

These study results suggest that tiered mitigation policies for cities at various economic development levels can help them find more effective carbon emissions mitigation paths. The strategies can include decarbonization of energy infrastructure and improvement of conservation and energy efficiency. In this way, considering the economic and development heterogeneity of cities, it would cause peak emissions from the building sector to occur before 2030; with a commensurate decline thereafter.

Liang et al., (2019), the fourth paper in this topic category, investigates the risks allocation mechanism of Public-Private Partnerships (PPP) renegotiation in Chinese environmental and urban governance industry and proposes a game theoretic model to anticipate the stakeholders' behaviors.

In view of the more complicated characteristics of stakeholders involved in the PPP projects in China, this study proposes a novel renegotiation risks allocation model to formulate risk management strategies in the environmental protection and urban governance field. In addition, the allocation of cooperative surpluses among the players involved is optimized based on a two-player bargaining game model and a multi-player coalitional game model in order to reach the optimal allocation of PPP renegotiation risks. A case study at a sewage disposal PPP project in Erhai Lake Basin is selected to verify the performance of the proposed models.

Research results of this study imply that when the government and private investors are renegotiating, they cannot simply distribute the surplus of cooperation evenly. Also, the renegotiation for the allocation of residual control should take full account of the ownership of project and the cooperative game process to optimize the allocation of surplus, so as to improve the effectiveness and efficiency of the decision makings in environmental multiparty PPP projects. In addition, it is essential to clarify the principles and mechanisms of PPP renegotiation and try to avoid the uncertainties and losses. Flexible clauses of the PPP contract may contribute to the reduction of unnecessary renegotiations and will provide references for response strategies to potential renegotiations in the future. 
Based upon these results, the authors suggest that all the participants should take rational and cautious behaviors and ensure the smooth implementation of urban PPP projects, while policy makers should prepare guidelines for developing appropriate governing principles or examining current rules and policies.

\section{Tools to accelerate the transitions to promote equitable, sustainable and livable cities}

Although a number of papers have shown various tools and methodologies for evaluating the research, broader applied tools that are feasible for implementation are also available. We expect such tools to facilitate the transition into post-fossil society and towards circular economy will become more common. Tools including holistic urban energy planning, closed-loop logistics distribution networks, and information platforms will play varying and important roles. These tools help to improve resource efficiency across the nexus of materials, energy, water and food, renewable energy transition, and integrated water management at the city level. Seven papers for this special issue primarily target this topical grouping.

Energy planning and urban planning are typically decoupled to encourage the use of renewable energy and consequently reduce greenhouse gas (GHG) emissions in megacities. Collaço et al. (2019) argue that a holistic urban energy planning strategy, integrating urban and energy planning, is desirable.

They propose an integrated solutions matrix for Urban and Energy Planning (UEP) strategies. They aim at quantifying UEP's sustainability gains potential for a megacity's energy system. The holistic and multi-sectoral approach for UEP integrated synergies assessment evaluates: (i) urban energy savings -- focusing not only on energy efficiency, but also on energy conservation; (ii) GHG emission reductions, and (iii) local and renewable energy system electricity production opportunities.

Twenty-nine UEP strategies for the Sao Paulo megacity in Brazil assess its energy system's sustainability gains using a Long-Range Energy Alternatives Planning System (LEAP) energy simulation model. The simulation characterizes the megacity's current and future energy systems. The results show that when both energy and urban planning approaches are integrated, energy savings (12\%), GHG emission reductions (30\%), and increase in renewable energy generation and distribution (four-fold) occurs. These results are higher than those when the traditional energy planning approach and urban planning strategies are decoupled.

Wang et al. (2019) develop a green urban closed-loop logistics distribution network model and evaluate it through one case study. The model's objective simultaneously minimizes an enterprise's eco-logical GHG emissions and overall economic operational cost. The proposed green logistics distribution model considers fuel cost, fixed cost, and carbon emissions. 
The case study involved three distribution centers providing distribution services to thirty customers. The results show a negative correlation between the distribution cost and carbon emissions under the shortest distribution routes. However, this negative correlation is not absolute. Certain changes in distribution cost may lead to positive correlation between the cost and carbon emissions.

Multi-objective Pareto optimization results show that the combination of vehicles, including electric vehicles and fuel vehicles, is able to effectively achieve a win-win scenario jointly improving carbon emissions and distribution costs. Furthermore, the proposed model provides valuable information to different enterprises to achieve low carbon distribution and for policy makers to promote a low carbon agenda, respectively.

A theme running through many of the papers in this special issue is to consider holistic and systemic tools, models and perspectives. Existing urban energy platforms are limited in their consideration of holistic optimization, typically focusing on targeted short-term benefits. These platforms typically require operators and managers with strong technical capabilities. To address these challenges, Pardo-García et al. (2019) emphasize the need to move from sectoral analysis and policies toward more generic comprehensive methods, tools and indicators. These comprehensive, holistic elements are more capable of designing long-term energy strategies.

They detail the design and development of the innovative "SureCity" platform. The platform can help cities achieve their mid-to-long term sustainability targets. It uses transparent and user-friendly software that non-technical staff, such as political leaders, can utilize. The software allows assessment of urban policies and measures through holistic energy system optimization. It also bridges scientific bottom-up models and city planning skills to perform urban neighborhood, district or city design. Although the SureCity platform developers target the needs for small and medium-sized European cities, it is also useful for larger cities.

Alexander et al. (2019) take a technological turn and explore the potential of using home-scale biogas systems. This technology is an alternative to a centralized system, for low-density residential landscapes and the management of food wastes. There is a reduction of fossil energy dependence from biogas production for cooking.

This study examines two home-scale biogas units operating in Melbourne, Australia to test the functionality and economic feasibility of small-scale, domestic biogas systems. Their results show that one household is able to cook on average 37.8 minutes each day for three months using the biogas produced from household level systems. These systems can reduce the household's dependence on fossil fuel-derived gas.

Using another advanced commercial model as a benchmark, the payback period for a home-scale biogas system is approximately 4.45 years, with some variances. This 
variance accrues from costs and savings of a home-scale biogas system depending on various factors. Cost factors include the value of the fertilizer produced by the unit and savings on service fees associated with the connection to the grid. Although this promising innovation can help reduce food waste and dependence on fossil fuels, the authors identify several challenges including the biogas digester's narrow temperature threshold, a lack of comprehensive government regulation, and a lack of consumer and community drive and knowledge.

Dong et al. (2018), the fourth article in this special issue topic, evaluates energy savings and carbon reduction potential of recycling wastes from a life cycle perspective. Taking Shanghai as the case study location, the authors quantify the embodied energy and $\mathrm{CO}_{2}$ emission from recycling all the recyclable wastes at the city level. Their results show that waste recycling of various wastes can achieve 8.7 million tons of coal equivalent (Mtce) of energy saving and $16.81 \mathrm{Mt} \mathrm{CO}_{2}$ of carbon emission reduction. These saving primarily occur from waste steel and nonferrous metal recycling.

The authors propose adoption of refuse plastic and paper fuel (RPF) technology to deal with the large quantity of non-recyclable wastes. This study investigates the potential energy savings and carbon emissions reduction from (i) increasing recycling rates and (ii) applying RPF. The results show that the total reduction potential can reach 7.69Mtce (energy savings) and 12.78 million tons $(\mathrm{Mt}) \mathrm{CO}_{2}$ (carbon emissions reduction). The contributions are $80-85 \%$ from increasing recycling rates and $10-15 \%$ from RPF technology implementation.

Maki et al., (2019) apply a Markov switching model to predict future energy demand of one wastewater treatment plant so that necessary energy conservation measures can be taken. A case study approach was employed to examine the effectiveness of this model in the Shinchi wastewater treatment plant in Shinchi town, Fukushima Prefecture, Japan.

This area suffered from the 2011 tsunami and earthquake and most of the local communities were devastated in that event. Energy supply shortage issues exist, therefore, it is crucial to improve the overall energy efficiency. In this regard, an online monitoring system was installed to measure energy consumption of this local wastewater treatment plant, covering energy consumption of water treatment process, sludge treatment process and other ancillary facilities. Data from this monitoring system can facilitate different stakeholders to work together to mitigate the overall energy consumption of this wastewater treatment plant. Also, the prediction results for its future energy consumption can further help identify the key energy consumption processes and seek the optimal solutions for future low carbon operation.

Simoe et al. (2019) presents an innovative optimization city-energy system model (ESM), based on the TIMES model generator, to promote holistic decision support for urban energy management in four European cities (Évora in Portugal, Cesena in Italy, 
Nottingham in UK and Trikala in Greece).

TIMES is a technology-rich, bottom-up optimization model integrating the entire energy/emission system of the city, including the procurement, transformation, trade, and consumption of a large number of energy forms. It generates future scenarios of cost-effective energy technologies, taking into consideration city planning goals and policies (e.g. expansion of a services hotspot in a specific city district, reducing the city overall GHG emissions, complying with a renewable target) while fulfilling the exogenous demand for energy services of the various city districts. Such a model can predict future energy flows, energy commodity prices, GHG and air quality emissions, new supply infrastructures and demand device purchases, total installed capacity of technologies and energy expenditures.

The results of this study indicate that the combination of this energy model with a MultiCriteria Decision Analysis (MCDA) allows for a more thorough assessment of different energy saving measures. They also suggest that the interactions between stakeholders are very useful for a more common understanding of the city energy system so that the optimum mix of measures for a sustainable urban energy future can be identified.

\section{Metrics and Indicators}

Metrics and indicators are invaluable in urban planning. The right information, data, measures and metrics are central for supporting urban administration. They are also necessary for almost all the tools, models, and planning that have appeared in each of the previous sections of this special issue. Both developing and developed urban settings benefit from historical data (quantity) and focal accuracy (quality) when acquiring data. Papers in this topical category provide alternative paths to guide urban administration toward post-fossil fuel city goals.

In the first paper in this special issue, Huang et al. (2019) account for Shanghai's building sector GHG emissions. They require this information to determine appropriate GHG emission mitigation measures. As can be seen in previous articles, the build environment is one of the largest and most important contributors to UEG.

Life cycle assessment and decoupling analysis, are used in this study to quantify GHG emissions. This study uncovers relationships between building materials consumption and local GDP growth. Their results show that concrete, brick, sand, gravel and cement are the main consumed materials; high GHG emission burden materials per kilogram include steel, lime, wood, glass and cement.

During the past 17 years the Shanghai building sector experienced a trend from integrated to relative decoupling between building material use and GDP. The results suggest that the control of high GHG emission burden materials -- steel and lime -energy use reduction, and the reduced use of $\mathrm{CO}_{2}$ intensive energy sources during manufacturing are most effective for lowering GHG emissions. Reducing consumption 
and seeking substitute materials with lower GHG burden per unit for highly consumed building materials, such as concrete and brick, is also effective.

The second paper in this topic is authored by Ma et al., (2019), who evaluate the built environment industry. Their study investigates whether carbon intensity in the commercial building sector is decoupled from economic development in the service industry. They complete this comparison at the national and the top five urban regions.

Five Chinese urban agglomerations, regions, were chosen as case study regions for the period 2000-2015. These locations include Jing-Jin-Ji (JJJ), Yangtze-River-Delta (YRD), Pearl-River-Delta (PRD), Yangtze-River-Middle-Reach (YRMR), and Cheng$\mathrm{Yu}(\mathrm{CY})$ urban agglomerations. Their results show that the nationwide decoupling status was weak from 2001-2005 and strengthened during the period of 2006-2015. At the urban agglomeration level, only four regions had a decoupling status.

The carbon Kuznets curves for the commercial building sector helps uncover the causes of decoupling paths from different urban agglomerations. The growing decoupling effects over the past decade are from the pervasive development and adoption of commercial building sector energy conservation projects. This study aids in predicting when carbon emissions will peak in the Chinese commercial building sector, supporting more appropriate mitigation policies.

In the third paper of this topic, Zhang and Wu (2018) turn to regulatory policy and metrics under legislated mandatory target systems. Whether these regulatory metrics and instruments are effective at improving the performance of urban environmental governance in China remains an open question.

The causal relationship between mandatory targets and haze pollution, particularly $\mathrm{PM}_{2.5}$ (particulate matter less than $2.5 \mu \mathrm{m}$ ) concentration reductions, are examined in 267 Chinese cities. This study applies a two-stage least square regression model and a spatial autoregressive model as the methodology. The results show that a $1 \%$ increase in mandatory $\mathrm{PM}_{2.5}$ performance targets helped reduce the annual average $\mathrm{PM}_{2.5}$ concentrations by $0.5283 \mu \mathrm{g} / \mathrm{m}^{3}$ on average after two years of implementation. Moreover, the $\mathrm{PM}_{2.5}$ concentrations of Chinese cities demonstrate strong positive spatial dependence. When spatial dependence is controlled, the average marginal impact of mandatory targets on $\mathrm{PM}_{2.5}$ concentration reduction decreased to 0.1998 $\mu \mathrm{g} / \mathrm{m}^{3}$. These results confirm the spatial aggregation of $\mathrm{PM}_{2.5}$ concentrations across Chinese cities and highlight the effectiveness of mandatory target systems for China's haze pollution control.

The fourth indicator and metrics paper, the topic of this section of the special issue, is authored by Zhou and Chen (2019). They propose three methods of district-level target decomposition to explore how municipal tasks can be determined to achieve a postfossil carbon city. 
Using carbon emissions and energy consumption predictions, the authors use Beijing, China as a case study urban environment to evaluate its achievement of carbon emissions reduction targets. The three methods in this study include: (i) average adjustment method -- emphasizing equity and operability; (ii) type assignment method - emphasizing operability and feasibility; and (iii) reduction pathway method -emphasizing more on equity and feasibility).

Their results indicate that in order to control total carbon dioxide emissions, two measures should be undertaken; controlling total energy consumption and expanding green electricity imports into Beijing. They find that future economic growth and energy consumption will rely on non-fossil fuel and imported green electricity. Academically, these methods can help evaluate carbon emissions reduction targets. The results can also inform carbon emissions reduction policies so that more cities can evolve toward low carbon development.

In the last paper of this topic, del Mar Martínez-Bravo et al. (2019) explores how the interplay between pollution and the three pillars of urban sustainability (economic, social and environmental) determines city livability. These relationships are tested using a structural equation model (SEM) in a sample of responses from citizens in 67 European cities and secondary data on urban pollution.

Their results indicate that cities are dynamic and complex systems that require holistic perspectives to be understood and managed. They propose that improvements in the economic, environmental and social sustainability of cities are goals that not only stand but also are important because they affect city livability. They also emphasize that translating economic progress into environmental (e.g., green areas, recycling, waste management) and social (e.g., social equity, access to basic services) sustainability might be even more critical in these contexts. Finally, they suggest that cities must invest their resources to increase environmental and social services and facilities so that economic development can effectively improve daily life.

\section{Conclusions}

This special volume includes 26 papers to address UEG. The ultimate goal of UEG is to identify sound pathways for transition to equitable post fossil-carbon societies. Regenerative and preventative thinking set the foundation for an integrated approach simultaneously addresses the many interconnected concerns and players. To meet the UN SDG goals, effective combinations of innovative policies, well-designed indicators, appropriate lifestyles and suitable behavior changes, and efficient tools are necessary.

Figure 1 presents our holistic framework, which brings together all the papers in this special issue and which help set the stage for effective urban environmental governance. 


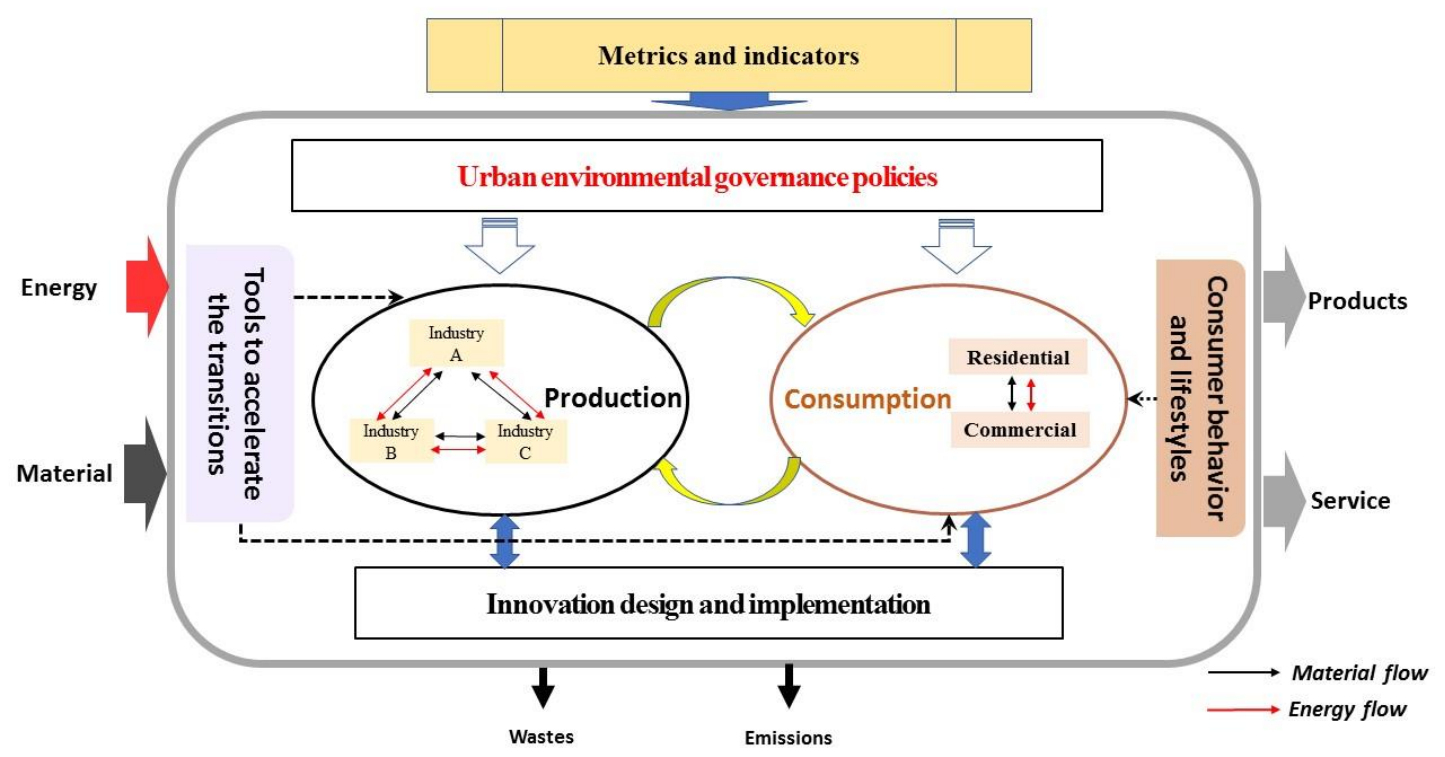

Figure 1. Framework of promoting urban environmental governance

Within this framework, innovative UEG policies provide appropriate guidance to practitioners. Varying governmental agencies need to cooperate for more effective policies. In particular, a concerted and consistent effort to promote UEG is critical. This effort needs to include efficient use of resources and reduce overall waste production.

Urban governance and regulatory mechanisms should consider adopting both a traditional "stick" policy - effective enforcement of environmental regulations -- and a "carrot" policy -- employing market and incentive mechanisms to promote UEG. The two-pronged approach is not groundbreaking, but flexibility is needed to support the identified innovations and actions. In the future, reconstruction and recovery from the built environment could reduce much of the material footprints of cities and their demolition waste, along with lower emissions.

Building knowledge and educating both industries and consumers about the issues for UEG is necessary. Understanding waste production, promoting prevention measures though tax redesign, financial subsidies, and resource pricing reform are policy tools that may be useful. The policy context varies in different cities and in different countries. Future concerns relating to a combination of policy localization and integration should be investigated for determination of the most effective mechanisms and regulatory infrastructure requirements. Stakeholder engagement and addressing informal settlements are key to dissemination of innovations and harnessing disruptive technologies. Social and regulatory exchange theory, as an example, relating organizations to regulatory and community relationships, can prove to be promising joint organizational-policy theoretical perspectives to advance knowledge and understanding in this area (Zhu et al., 2018). There are also many other policy process theories that can be investigated and applied for sustainability transitions (see Kern and 
Rogge (2018), for a review of some major theories).

Well-designed indicators are useful for directing effective UEG. Although some major assessment methods appear in this special issue, no single method can address the holistic nature of UEG. The balance of both economic development and ecological protection is a complex and 'wicked' problem. A rational approach is to combine different assessment methods where both "donor-side" and "supply-side" of urban metabolism can be examined and environmental impacts can be assigned equitably. In this regard, holistic and multiple methods can help discourage inefficient and unnecessary resource depletion, a key UEG target.

Sustainable lifestyles and human behaviors are important catalysts in UEG. It is necessary to pursue feedback from communities and consumers to support better design of practical policies. Various capacity-building efforts should be initiated to help the public improve their awareness and knowledge. Using social media, popular television promotions, regular workshops, pamphlets, newspapers, and community organizing can all be capacity-building efforts.

Smart design and effective implementations can help promote UEG. It is expected that in the future more synergistic opportunities, such as urban and industrial symbiosis, urban energy and water cascading, can be identified and implemented. Feasible business models are necessary to finance and capitalize these transitioning projects. It will be good if cities adopt missions and policy roadmaps on their future directions thus aligning various actors and pooling innovation efforts. In addition, more comparative studies of UEG in different regions should be initiated so that experiences and lessons can be learned and shared worldwide. For example, a number of regions with megaurban areas were not investigated in this special issue; some in developing regions of the world such as Africa and some in the most developed regions of the world such as the USA.

Innovative and holistic tools can provide policy, organizational, and community decision support. Life cycle thinking, a range of footprint methods and nexus approaches, design for sustainable production and consumption, can be useful to practical and policy contexts. Future challenges for the integration of modeling approaches include investigating multiple levels; verification and localization of current meso- and macro- level models, as well as collaborative research on the difficulty of developing common frameworks and reconciling different methodological approaches. In addition, UEG requires concrete and practical planning tools so that dynamics of socioeconomic development and urban activities can be combined with technology-based models.

In general, policies, indicators, consumer issues, innovative designs and tools interact with each other and contribute to the objective of UEG. As for the interactions between different aspects, after policy design and implementation, indicators, designs and tools 
can be adopted to evaluate the corresponding impacts on both the urban environment and its economy. Such impacts provide feedback to policy design for better adjustment, selection, and eventual application for sustainability transitions. Evaluation results from indicators and tools can guide the consumer behaviors to move toward sustainable consumption. Improved consumer lifestyles and behaviors can be evaluated using indicators and tools. All five dimensions in this framework need to work together to support final implementation.

Effective UEG is expected to support sustainable urban development. This development includes planning for sustainable infrastructure in developing countries to address a new wave of urbanization. The UEG needs to address the emergent nexus of resource-energy-water issues as well as economic and environmental regeneration in developed countries (Bleischwitz et al. 2018).

This special issue provides numerous innovations for UEG and accelerating the transition to equitable, sustainable, and livable cities. We do this with an especial focus on post-fossil carbon societies. But, this special issue is only a touch point. We feel the research has only commenced; there is a desperate need for application of this research and more innovation. We hope to have encouraged more of these efforts by building a stronger foundation.

Acknowledgement: This study is supported by the Natural Science Foundation of China (71810107001, 71690241), the Shanghai Municipal Government (17XD1401800), and the big data project funded by Shanghai Jiao Tong University (SJTU-2019UGBD-03).

\section{References:}

Akbari, M., Hopkins, J.L., 2019. An investigation into anywhere working as a system for accelerating the transition of Ho Chi Minh city into a more livable city. Journal of Cleaner Production 209, 665 679.

Alexander, S., Harris, P., McCabe, B.K., 2019. Biogas in the suburbs: An untapped source of clean energy? Journal of Cleaner Production.

Bai, X. et al. (2018) Six research priorities for cities and climate change, Nature 555, 23 - 25.

Bleischwitz R. et al. (2018) Resource nexus perspectives towards the United Nations Sustainable Development Goals, Nature Sustainability 1, 737 - 743

Chen, H., Chen, W., 2019. Carbon mitigation of China's building sector on city-level: pathway and policy implications by a low-carbon province case study. Journal of Cleaner Production.

Collaço, F.M.d.A., Simoes, S.G., Dias, L.P., Duic, N., Seixas, J., Bermann, C., 2019. Gordon the dawn of urban energy planning - Synergies between energy and urban planning for São Paulo (Brazil) megacity. Journal of Cleaner Production 215, 458-479.

Czischke, D., Pascariu, S., 2015. New Concepts and Tools for Sustainable Urban Development in 2014 - 2020. URBACT Study.

Dong, H., Geng, Y., Yu, X., Li, J., 2018. Uncovering energy saving and carbon reduction potential from 
recycling wastes: A case of Shanghai in China. Journal of Cleaner Production 205, 27-35.

del Mar Martínez-Bravo, M., Martínez-del-Río, J., Antolín-López, R., 2019. Trade-offs among urban sustainability, pollution and livability in european cities. Journal of Cleaner Production.

Fan, J.-s., Zhou, L., 2019. Impact of urbanization and real estate investment on carbon emissions: Evidence from China's provincial regions. Journal of Cleaner Production 209, 309-323.

Fratini, C. F., Georg, S., \& Jørgensen, M. S., 2019. Exploring circular economy imaginaries in European cities: a research agenda for the governance of urban sustainability transitions. Journal of Cleaner Production.

Fujii, M., Fujita, T., Ohnishi, S., Yamaguchi, N., Yong, G., Park, H.S., 2014. Regional and temporal simulation of a smart recycling system for municipal organic solid wastes. Journal of Cleaner Production 78, 208-215.

Geng, Y., Sarkis, J., Bleischwitz, R., 2019. How to globalize the circular economy. Nature 565: 153-155.

Gil, J., Duarte, J.P., 2013. Tools for evaluating the sustainability of urban design: a review. Proceedings of the Institution of Civil Engineers-Urban Design and Planning 166, 311-325.

Huang, B., Chen, Y., McDowall, W., Türkeli, S., Bleischwitz, R., Geng, Y., 2019. Embodied GHG emissions of building materials in Shanghai. Journal of Cleaner Production 210, 777-785.

Kern, F., \& Rogge, K. S. (2018). Harnessing theories of the policy process for analysing the politics of sustainability transitions: A critical survey. Environmental innovation and societal transitions, 27, 102117.

Khuong, P.M., McKenna, R., Fichtner, W., 2019. Analyzing drivers of renewable energy development in Southeast Asia countries with correlation and decomposition methods. Journal of Cleaner Production 213, 710-722.

Li, Y., Zeng, B., Wu, T., Hao, H., 2019a. Effects of urban environmental policies on improving firm efficiency: Evidence from Chinese new energy vehicle firms. Journal of Cleaner Production 215, 600610.

Li, B., Wang, F., Yin, H., Li, X., 2019b. Mega Events and Urban Air Quality Improvement: A Temporary Show? Journal of Cleaner Production.

Liang, Q., Hu, H., Wang, Z., Hou, F., 2019. A Game Theory Approach for the Renegotiation of PublicPrivate Partnership Projects in Chinese Environmental and Urban Governance. Journal of Cleaner Production.

Ma, M., Cai, W., Cai, W., Dong, L., 2019. Whether carbon intensity in the commercial building sector decouples from economic development in the service industry? Empirical evidence from the top five urban agglomerations in China. Journal of Cleaner Production.

Maki, S., Chandran, R., Fujii, Minoru., Fujita, T., Shiraishi, Y., Ashina, S., Yabe, N., Mr., 2019. Innovative information and communication technology (ICT) system for energy management of public utilities in a post-disaster region: Case study of a wastewater treatment plant in Fukushima. Journal of Cleaner Production.

Pardo-García, N., Simoes, S.G., Dias, L., Sandgren, A., Suna, D., Krook-Riekkola, A., 2019. Sustainable and Resource Efficient Cities platform - SureCity holistic simulation and optimization for smart cities. Journal of Cleaner Production 215, 701-711.

Qu, Y., Zhu, Q., Sarkis, J., Geng, Y., \& Zhong, Y. 2013. A review of developing an e-wastes collection system in Dalian, China. Journal of cleaner production, 52, 176-184.

Runhaar, H., Driessen, P.P.J., Soer, L., 2009. Sustainable urban development and the challenge of policy integration: an assessment of planning tools for integrating spatial and environmental planning in the 
Netherlands. Environment and Planning B-Planning \& Design 36, 417-431.

Schröder, P., Vergragt, P., Brown, H.S., Dendler, L., Gorenflo, N., Matus, K., Quist, J., Rupprecht, C.D.D., Tukker, A., Wennersten, R., 2019. Advancing sustainable consumption and production in cities A transdisciplinary research and stakeholder engagement framework to address consumption-based emissions and impacts. Journal of Cleaner Production 213, 114-125.

Shi, J., Zhou, J., Zhu, Q., 2019. Barriers of a closed-loop cartridge remanufacturing supply chain for urban waste recovery governance in China. Journal of Cleaner Production 212, 1544-1553.

Simoes, S. G., Dias, L., Gouveia, J. P., Seixas, J., De Miglio, R., Chiodi, A., Gargiulo, M., Giannakidis, G., 2019. InSmart-A methodology for combining modelling with stakeholder input towards EU cities decarbonisation. Journal of Cleaner Production.

Song, G., Semakula, H.M., Fullana-i-Palmer, P., 2018. Chinese household food waste and its' climatic burden driven by urbanization: A Bayesian Belief Network modelling for reduction possibilities in the context of global efforts. Journal of Cleaner Production 202, 916-924.

Tian, X., Geng, Y., Dai, H.C., Fujita, T., Wu, R., Liu, Z., Masui, T., Yang, X., 2016. The effects of household consumption pattern on regional development: A case study of Shanghai. Energy 103, 4960.

Valenzuela-Levi, N., 2019. Do the rich recycle more? Understanding the link between income inequality and separate waste collection within metropolitan areas. Journal of Cleaner Production 213, 440-450.

Wang, J., Lim, M.K., Tseng, M.-L., Yang, Y., 2019. Promoting low carbon agenda in the urban logistics network distribution system. Journal of Cleaner Production 211, 146-160.

Weber, G., Frahm, L.G.,Cabras, I., 2019. De-privatisation and Remunicipalisation of Urban Services for More Sustainable Cities: The Case of Germany. Journal of Cleaner Production.

Wu, F., Geng, Y., Tian, X., Zhong, S., Wu, W., Yu, S., Xiao, S., 2018. Responding climate change: A bibliometric review on urban environmental governance. Journal of Cleaner Production 204, 344-354.

Zhang, P., Wu, J., 2018. Impact of mandatory targets on PM2.5 concentration control in Chinese cities. Journal of Cleaner Production 197, 323-331.

Zhou, L., Chen, W., 2019. Impact of district-level decomposition policies to achieve a post-fossil carbon city: a case study of Beijing, China. Journal of Cleaner Production.

Zhu, Q., Sarkis, J., \& Lai, K. H. (2018). Regulatory policy awareness and environmental supply chain cooperation in China: A regulatory-exchange-theoretic perspective. IEEE Transactions on Engineering Management, 65(1), 46-58. 